\title{
Carbon film resistor electrode for amperometric determination of acetaminophen in pharmaceutical formulations
}

\author{
Fabiana S. Felix ${ }^{a}$, Christopher M.A. Brett ${ }^{b}$, Lúcio Angnes ${ }^{a}{ }^{a} *$ \\ ${ }^{a}$ Instituto de Química, Universidade de São Paulo, CP 26077, 05599-970 São Paulo, Brazil \\ ${ }^{\mathrm{b}}$ Departamento de Química, Universidade de Coimbra, 3004-535 Coimbra, Portugal
}

Received 28 June 2006; received in revised form 22 November 2006; accepted 29 November 2006

Available online 9 January 2007

\begin{abstract}
Flow injection analysis (FIA) with amperometric detection was employed for acetaminophen quantification in pharmaceutical formulations using a carbon film resistor electrode. This sensor exhibited sharp and reproducible current peaks for acetaminophen without chemical modification of its surface. A wide linear working range $\left(8.0 \times 10^{-7}\right.$ to $\left.5.0 \times 10^{-4} \mathrm{~mol} \mathrm{~L}^{-1}\right)$ in phosphate buffer solution as well as high sensitivity $\left(0.143 \mathrm{~A} \mathrm{~mol}^{-1} \mathrm{~L} \mathrm{~cm}^{-2}\right)$ and low submicromolar detection limit $\left(1.36 \times 10^{-7} \mathrm{~mol} \mathrm{~L}^{-1}\right)$ were achieved. The repeatability (R.S.D. for 10 successive injections of $5.0 \times 10^{-6}$ and $5.0 \times 10^{-5} \mathrm{~mol} \mathrm{~L}^{-1}$ acetaminophen solutions) was 3.1 and $1.3 \%$, respectively, without any memory effect between injections. The new procedure was applied to the analyses of commercial pharmaceutical products and the results were in good agreement with those obtained utilizing a spectrophotometric method. Consequently, this amperometric method has been shown to be very suitable for quality control analyses and other applications with similar requirements.
\end{abstract}

(c) 2006 Elsevier B.V. All rights reserved.

Keywords: Flow injection analysis; Carbon film resistor electrodes; Acetaminophen; Amperometry

\section{Introduction}

Acetaminophen ( $N$-acetyl- $p$-aminophenol, 4-acetamidophenol, paracetamol or tylenol) is a popular analgesic and antipyretic agent. Its action is similar to aspirin and is an appropriate alternative for patients who are sensitive to acetylsalicylic acid [1]. The development of analytical techniques for the rapid analysis of paracetamol is important for quality and medical control. Overdose ingestions of acetaminophen lead to accumulation of toxic metabolites, which may cause severe and sometimes fatal hepatotoxicity and nephrotoxicity [2-4]. This drug is available in different dosage forms of tablets, capsules, suspensions and suppositories.

Kissinger et al. [5,6] investigated the electrochemical oxidation of acetaminophen through cyclic voltammetric studies. The first reaction step is an electrochemical oxidation involving two electrons and two protons to generate $N$-acetyl- $p$-quinoneimine. All subsequent reaction steps are non-electrochemical, but $\mathrm{pH}$ -

\footnotetext{
* Corresponding author. Tel.: +55 113091 3828; fax: +55 1138185579.

E-mail address: luangnes@iq.usp.br (L. Angnes).
}

dependent, processes. For oxidations at $\mathrm{pH}$ values $\geq 6$, the final product is a benzoquinone.

For the quantification of acetaminophen in pharmaceutical products, the American Pharmacopoeia recommends liquid chromatography as the official method [7] while the Brazilian Pharmacopoeia uses a spectrophotometric technique [8]. Moreover, there are many studies described in the literature for determination of this drug.

These include spectrophotometry [9-11], chemiluminescence [12,13], liquid chromatography [14], capillary electrophoresis [15,16], amperometric biosensors [17-19], amperometric batch injection analysis [20], colorimetry [21], titrimetry [22] and FTIR-spectrometry [23]. Flow injection analysis (FIA) using UV-vis spectrophotometric detection has been demonstrated in several papers to be appropriate for acetaminophen determination [24-28], but these spectrophotometric methods require special reagents and are time consuming, not constituting a rapid analytical method.

Many voltammetric studies involving acetaminophen quantification utilize chemically modified electrodes [29-33] or boron doped diamond electrodes [34] in order to improve the sensitivity. To the best of our knowledge, there is no other report 
in the literature of flow injection studies utilizing unmodified electrodes for acetaminophen quantification in pharmaceutical formulations. The possible use of unmodified electrodes is an attractive alternative to investigate, since it leads to simplification of the analytical procedure and a decrease in analysis time, particularly in flow analysis.

This paper reports the electrochemical determination of acetaminophen in different pharmaceutical tablets at carbon film electrodes, without any sample pretreatment or electrode modification being necessary. These carbon film electrodes, fabricated from carbon resistors of $2 \Omega$ nominal resistance, have a wide potential window (for both positive and negative limits) than many other forms of carbon, the detector preparation is very easy and they have already been employed in a variety of electroanalytical experiments involving its characterization [35,36], trace metal analysis [37,38] and its utilization for biosensor construction [39-42]. Cyclic voltammetry characterization and determinations by flow injection analysis with amperometric detection were performed, at the carbon film electrode inserted in a flow cell. In the flow injection procedure, a wide linear working range, high sensitivity and submicromolar detection limit were achieved, without any memory effect between injections.

\section{Experimental}

\subsection{Reagents and solutions}

Acetaminophen, caffeine, L-ascorbic acid, citric acid, lactose and glucose were obtained from Sigma (St. Louis, Mo, USA). Sodium hydroxide, sulphuric acid, sodium monohydrogen phosphate and potassium dihydrogen phosphate were acquired from Merck (Darmstadt, Germany). All aqueous solutions were freshly prepared by dissolving the solid salt in $0.1 \mathrm{~mol} \mathrm{~L}^{-1}$ phosphate buffer electrolyte solution. The $\mathrm{pH}$ $(2-12)$ of the solutions was adjusted to the required value by addition of aliquots of $1.0 \mathrm{~mol} \mathrm{~L}^{-1}$ sulphuric acid or $2.0 \mathrm{~mol} \mathrm{~L}^{-1}$ sodium hydroxide. All solutions were prepared with ultrapure water from a Millipore Milli-Q system (resistivity $\geq 18$ $\mathrm{M} \Omega \mathrm{cm}$ ). The pharmaceutical products were purchased in a local drugstore.

\subsection{Electrode preparation}

Carbon film resistor ( $2 \Omega$ nominal resistance) electrodes, having a carbon film of $\sim 15 \mu \mathrm{m}$ thickness, were fabricated from ceramic cylinders with $4-6 \mathrm{~mm}$ length and $1.5 \mathrm{~mm}$ external diameter by pyrolytic deposition of carbon from methane in a nitrogen atmosphere [35] and have been characterized by electrochemical impedance [36]. Each resistor has two tightfitting metal caps and connecting wire as external contact. To make the electrodes, one of these metal caps was removed and other was covered by epoxy resin and the wire by a plastic sheath. The exposed cylindrical area of the electrode was $0.17 \mathrm{~cm}^{2}$. The electrode was electrochemically pretreated with perchloric acid $1.0 \mathrm{~mol} \mathrm{~L}^{-1}$ at a scan rate of $100 \mathrm{mV} \mathrm{s}^{-1}$ [35].

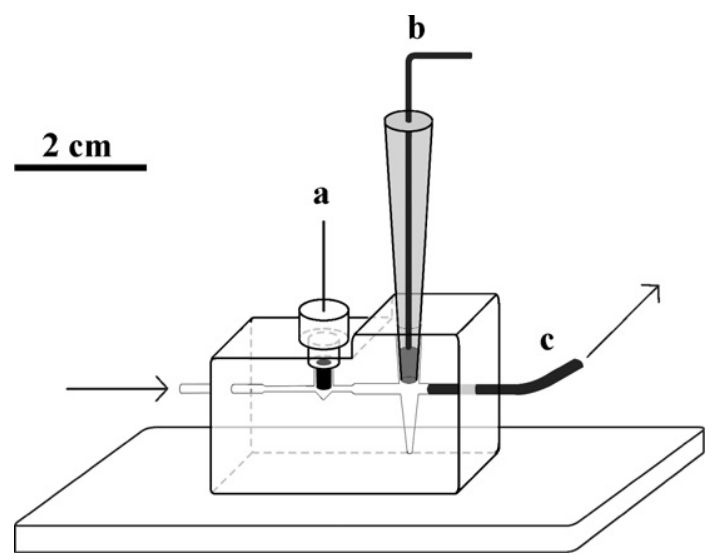

Fig. 1. Schematic representation of the electrochemical cell used for amperometric determination of acetaminophen: (a) carbon film working electrode, (b) $\mathrm{Ag} \mid \mathrm{AgCl}$ reference electrode and (c) stainless steel auxiliary electrode.

\subsection{Instrumentation and flow cell}

Cyclic voltammetric and amperometric measurements were carried out with an ECO Chemie Autolab PSTAT 20 potentiostat (EcoChemie, The Netherlands). Cyclic voltammetric studies were done in a conventional $10 \mathrm{~mL}$ cell. The FIA/amperometric experiments were performed utilizing the flow cell depicted in Fig. 1. This cell was constructed in Plexiglas and has a three electrode configuration with a carbon film resistor working electrode, an $\mathrm{Ag} / \mathrm{AgCl}_{\text {sat }}(\mathrm{sat} \mathrm{KCl}$ ) reference electrode and a stainless steel tube auxiliary electrode.

A peristaltic pump (Ismatec, Zurich, Switzerland) was employed for fluid propulsion. The manifold was built with polyethylene tubes $(0.8 \mathrm{~mm}$ i.d.). The standard solutions and acetaminophen samples were introduced into the stream through a manually operated injection valve.

\subsection{Sample and standard preparation}

Each tablet of commercial drug was initially dissolved in a $100 \mathrm{~mL}$ volumetric flask, using deionized water. Then, aliquots of 100 and $150 \mu \mathrm{L}$ (for tablets containing 750 and $500 \mathrm{mg}$ of acetaminophen, respectively) were transferred to a volumetric flask of $100 \mathrm{~mL}$ and the flask filled with phosphate buffer. The standard solutions of acetaminophen were prepared daily in a similar way, in the same phosphate buffer solution.

\section{Results and discussion}

\section{1. pH dependence study}

The electrochemical behavior of acetaminophen was investigated over the $\mathrm{pH}$ range from 2 until 12. Fig. 2 shows cyclic voltammograms of $1.0 \times 10^{-4} \mathrm{~mol} \mathrm{~L}^{-1}$ acetaminophen in $0.1 \mathrm{~mol} \mathrm{~L}^{-1}$ phosphate buffer solutions. It was observed that the oxidation potential decreased when the $\mathrm{pH}$ of the acetaminophen solution increased. This behavior was attributed to an increasing amount of hydrolysis that occurs as the $\mathrm{pH}$ is increased, leading to the formation of reducing compounds such as $p$ - 


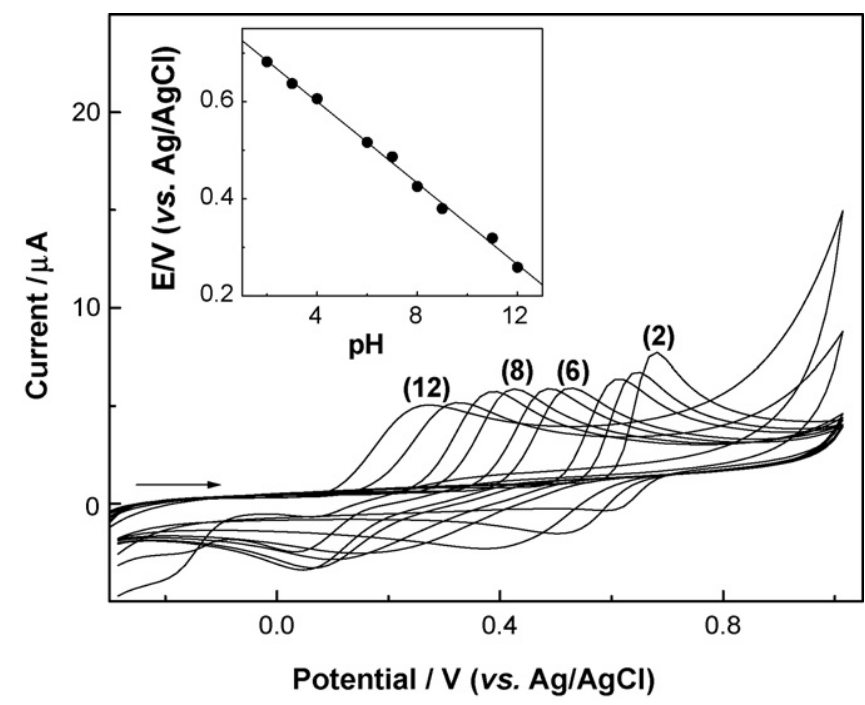

Fig. 2. Cyclic voltammograms of $1.0 \times 10^{-4} \mathrm{~mol} \mathrm{~L}^{-1}$ acetaminophen in $0.1 \mathrm{~mol} \mathrm{~L}^{-1}$ phosphate buffer solution at different $\mathrm{pH}$ (from 2 until 12). Carbon film electrode area $=0.17 \mathrm{~cm}^{2}$. Scan rate $100 \mathrm{mV} \mathrm{s}^{-1}$.

hydroxyaniline [34]. The negative shift in anodic peak potential $\left(E_{\mathrm{pa}}\right)$ with $\mathrm{pH}$ can be described by the equation:

$E_{\text {pa }}(\mathrm{V}$ vs. $\mathrm{Ag} / \mathrm{AgCl})=+0.76-0.042\{\mathrm{pH}\}$

The theoretical slope of the plot of $E_{\mathrm{pa}}$ versus $\mathrm{pH}$ for a classical Nernstian two-electron, two-proton process is $-59 \mathrm{mV} \mathrm{pH}^{-1}$. A slope of $-42 \mathrm{mV} \mathrm{pH}^{-1}$ was obtained in these experiments. This value is close to that found by Gilmartin and Hart [43] who reported a slope of $-46.5 \mathrm{mV} \mathrm{pH}^{-1}$ over a similar range of $\mathrm{pH}$ to that utilized here. These authors suggest a more complex oxidation mechanism for acetaminophen. When the $\mathrm{pH}$ is increased above 10 , the oxidation become kinetically less favorable, and adsorption of analyte on the electrode surface occurs more intensely. This is presumably due to the presence of the phenoxide form.

Under more acidic conditions (i.e. $\mathrm{pH} 2.0$ ) the oxidation potential increases significantly and a poorly defined cathodic wave for the reduction of $N$-acetyl-p-quinoneimine (NAPQI) was observed. In accordance with Kissinger et al. [5], this occurs because the hydration of the NAPQI molecule leads to its disappearance from the voltammogram. These authors concluded that all the protonated NAPQI is converted into the inactive hydrated form before negative potentials are reached during the reverse scan of the cyclic voltammetric experiment.

The selection of a suitable $\mathrm{pH}$ involved a compromise between sensitivity and the electrochemical behavior of acetaminophen in acidic and alkaline solution. Therefore, $\mathrm{pH}$ 8.0 was selected for further studies.

\subsection{Cyclic voltammetry}

Fig. 3 shows typical cyclic voltammetric curves for $1.0 \times 10^{-4} \mathrm{~mol} \mathrm{~L}^{-1}$ acetaminophen in $0.1 \mathrm{~mol} \mathrm{~L}^{-1}$ phosphate buffer solution $(\mathrm{pH} 8)$ at carbon film (solid line) and glassy carbon electrodes (dashed line). The carbon film exhibited a more well-defined peak at a less positive potential $(+0.4 \mathrm{~V}$ ver-

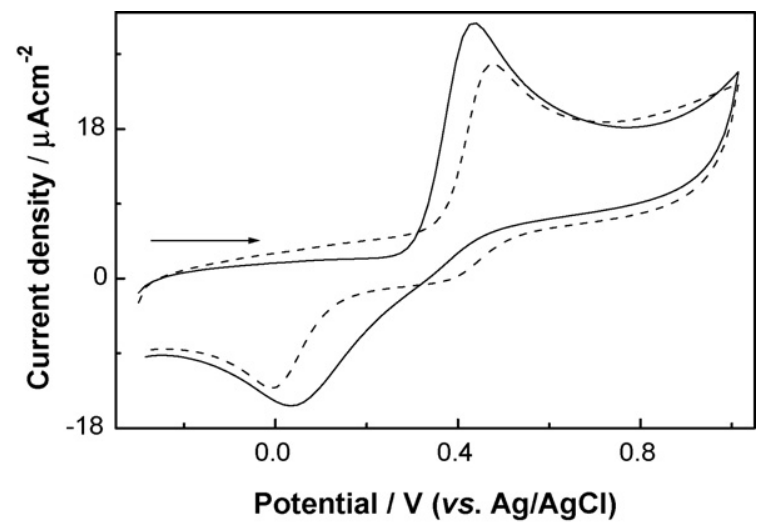

Fig. 3. Cyclic voltammograms of the carbon film (dotted line) and glassy carbon (solid line) electrodes in $0.1 \mathrm{~mol} \mathrm{~L}^{-1}$ phosphate buffer solution ( $\mathrm{pH}$ 8) containing $1.0 \times 10^{-4} \mathrm{~mol} \mathrm{~L}^{-1}$ acetaminophen. Electrode areas: $0.17 \mathrm{~cm}^{2}$ for carbon film and $0.18 \mathrm{~cm}^{2}$ for glassy carbon. Scan rate $100 \mathrm{mV} \mathrm{s}^{-1}$.

sus $\mathrm{Ag} / \mathrm{AgCl})$. Therefore, this new sensor is more favorable for detection of acetaminophen, since it should be less subject to interferences.

The variation of current with scan rate, from 0.01 until $0.9 \mathrm{~V} \mathrm{~s}^{-1}$, was investigated using $1.0 \times 10^{-4} \mathrm{~mol} \mathrm{~L}^{-1}$ acetaminophen in $0.1 \mathrm{~mol} \mathrm{~L}^{-1}$ phosphate buffer solution at pH 8, Fig. 4. An increase in the height of the oxidation and reduction waves occurred and peak potentials shifted towards more positive and negative values for oxidation and reduction processes, respectively. The oxidation and reduction peak currents varied linearly with the square root of scan rate $\left(v^{1 / 2}\right)$ with $r>0.999$, indicating that the electrochemical reaction is a diffusion-controlled process. The insets in Fig. 4 display the relationship between anodic and cathodic currents and scan rate; the ratio between oxidation and reduction currents was independent of scan rate at around 1.7. By applying the Randles-Sevcik equation to the oxidation process [44], an apparent diffusion coefficient for paracetamol of $1.5 \times 10^{-6} \mathrm{~cm}^{2} \mathrm{~s}^{-1}$ was obtained.

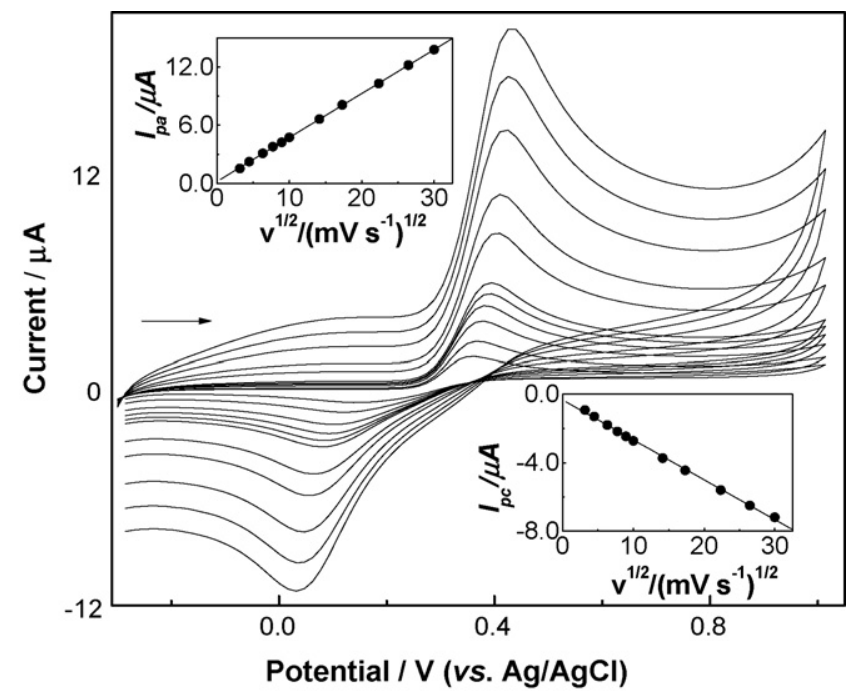

Fig. 4. Cyclic voltammograms of $1.0 \times 10^{-4} \mathrm{~mol} \mathrm{~L}^{-1}$ acetaminophen in $0.1 \mathrm{~mol} \mathrm{~L}^{-1}$ phosphate buffer solution $(\mathrm{pH} 8)$ at different scan rates. The insets show the relationship between anodic and cathodic currents with scan rate, $v$. 


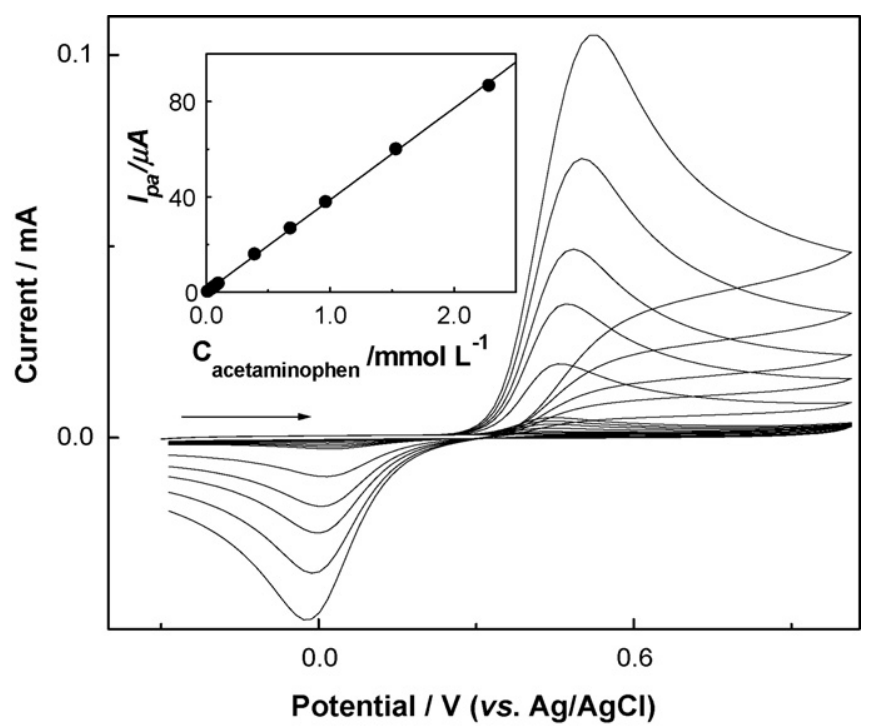

Fig. 5. Cyclic voltammograms obtained with carbon film electrode $(A=$ $\left.0.17 \mathrm{~cm}^{2}\right)$ in $0.1 \mathrm{~mol} \mathrm{~L}^{-1}$ phosphate buffer solution $(\mathrm{pH}$ 8) containing acetaminophen in different concentrations $\left(1.0 \times 10^{-5}\right.$ until $2.0 \times 10^{-3}$ $\mathrm{mol} \mathrm{L}^{-1}$ ). Scan rate $100 \mathrm{mV} \mathrm{s}^{-1}$.

Fig. 5 shows cyclic voltammograms resulting from increasing additions of acetaminophen in $0.1 \mathrm{~mol} \mathrm{~L}^{-1}$ phosphate buffer solution at scan rate $0.10 \mathrm{~V} \mathrm{~s}^{-1}$ at carbon film electrode. The signal obtained for each concentration of acetaminophen was very stable and reproducible. A very good linear relationship between current and acetaminophen concentration $\left(1.0 \times 10^{-5}\right.$ until $2.0 \times 10^{-3} \mathrm{~mol} \mathrm{~L}^{-1}$ ) was observed as can be seen in the inset of Fig. 5.

\subsection{Flow injection parameters}

To determine the optimal conditions for the flow injection system performance, the parameters such as sample volume and flow rate were varied using $1.0 \times 10^{-5} \mathrm{~mol} \mathrm{~L}^{-1}$ acetaminophen in $0.1 \mathrm{~mol} \mathrm{~L}^{-1}$ phosphate buffer $(\mathrm{pH}$ 8). An applied potential of $+0.6 \mathrm{~V}$ versus $\mathrm{Ag} / \mathrm{AgCl}$ was used in all these experiments, to ensure complete analyte oxidation.

The effect of flow rate (from 1.0 to $5.0 \mathrm{~mL} \mathrm{~min}^{-1}$ ) on the analytical signal was evaluated. The current increased with flow rate up until $3.0 \mathrm{~mL} \mathrm{~min}^{-1}$ and remained virtually constant for higher flow rates. A flow rate of $2.0 \mathrm{~mL} \mathrm{~min}^{-1}$ was selected for further experiments, which combines good sensitivity with a good sample analysis rate (50 determinations per hour). The effect of sample volume was also evaluated using injection loops from 50 up to $300 \mu \mathrm{L}$. The amperometric signal increased almost linearly with sample volume from 50 until $150 \mu \mathrm{L}$. For higher volumes, the increase was less significant. A volume of $150 \mu \mathrm{L}$ was chosen based on the best compromise between reproducibility and sampling rate.

\subsubsection{Analytical characteristics}

Under the optimized conditions, series of triplicate experiments were carried out using acetaminophen standard solutions in $0.1 \mathrm{~mol} \mathrm{~L}^{-1}$ phosphate buffer electrolyte at $\mathrm{pH}$ 8. Lin-

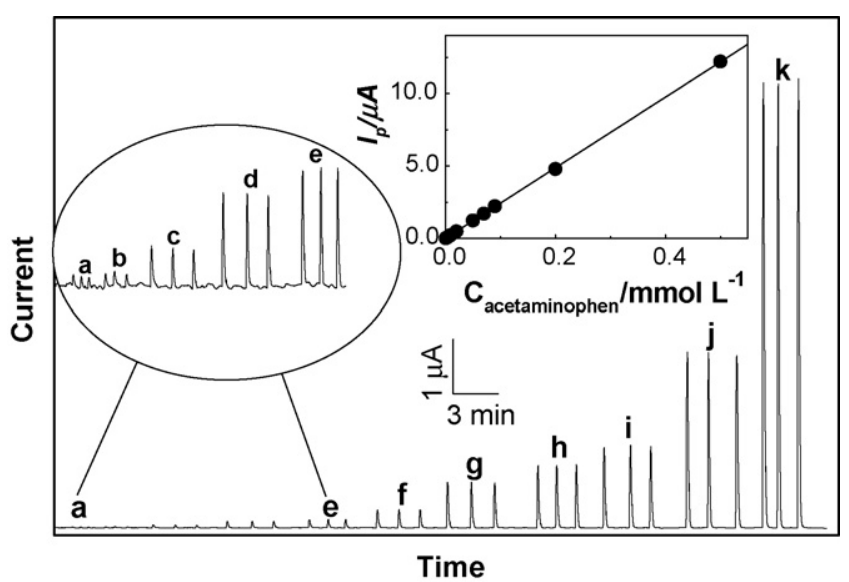

Fig. 6. FIA results for a carbon film electrode $\left(A=0.17 \mathrm{~cm}^{2}\right)$ in $0.1 \mathrm{~mol} \mathrm{~L}^{-1}$ phosphate buffer electrolyte, $\mathrm{pH} 8$, after injections of (a) $8.0 \times 10^{-7}$, (b) 1.0 , (c) 3.0 , (d) 7.0 , (e) $9.0 \times 10^{-6}$, (f) 2.0 , (g) 5.0 , (h) 7.0 , (i) $9.0 \times 10^{-5}$, (j) 2.0, (k) $5.0 \times 10^{-4} \mathrm{~mol} \mathrm{~L}^{-1}$ acetaminophen. Applied potential $+0.6 \mathrm{~V}$ vs. $\mathrm{Ag} / \mathrm{AgCl}$, flow rate $2.0 \mathrm{~mL} \mathrm{~min}^{-1}$, sample loop $150 \mu \mathrm{L}$. The inset shows the calibration plot.

earity between FIA current and acetaminophen concentration was observed over a wide range, from $8.0 \times 10^{-7}$ up to $5.0 \times 10^{-4} \mathrm{~mol} \mathrm{~L}^{-1}$. All acetaminophen standard solutions were made by dilution from a $5.0 \times 10^{-3} \mathrm{~mol} \mathrm{~L}^{-1}$ stock solution. Fig. 6 shows a series of current peaks obtained in one of these series of experiments. The dynamic range had a slope of $24.34 \pm 0.07 \mu \mathrm{A} / \mathrm{mM}$, and an intercept of $0.004 \pm 0.011 \mu \mathrm{A}$ with a correlation coefficient of 0.999 . The estimated detection limit was $1.36 \times 10^{-7} \mathrm{~mol} \mathrm{~L}^{-1}$ (three times the blank standard deviation/slope) and the quantification limit was calculated as $4.53 \times 10^{-7} \mathrm{~mol} \mathrm{~L}^{-1}$.

Comparing the results obtained here with some other studies, the linear range obtained with the carbon film resistor electrodes is wider than those obtained by other techniques or utilizing different sensors $[19,20,34]$. The detection limit of this sensor compares favorably with the one obtained utilizing gold electrodes were modified with thiols [30] and is situated just below the value obtained when boron doped diamond electrodes were utilized [34]. Comparing voltammetry and other techniques, chemiluminescence leads to the lower detection limits (in the low nanomolar region $[12,13])$, whereas spectrophotometry presented higher limits (micromolar region $[24,27,28]$ ).

Fig. 7 shows repetition of alternate injections of $150 \mu \mathrm{L}$ of $5.0 \times 10^{-6}$ and $5.0 \times 10^{-5} \mathrm{~mol} \mathrm{~L}^{-1}$ acetaminophen in $0.1 \mathrm{~mol} \mathrm{~L}^{-1}$ phosphate buffer electrolyte. In this experiment, the excellent repeatability of the current peaks for both concentrations is seen. Additionally, there is no memory effect during the injections, demonstrating that there has been no poisoning of the electrode surface. Results from this series of injections gave relative standard deviations (R.S.D.) of 3.1 and $1.3 \%$ for $5.0 \times 10^{-6}$ and $5.0 \times 10^{-5} \mathrm{~mol} \mathrm{~L}^{-1}$ acetaminophen solutions, respectively.

\subsubsection{Interference studies}

The effect of possible interferences was investigated by addition of other compounds to a solution containing $1.0 \times 10^{-5} \mathrm{~mol} \mathrm{~L}^{-1}$ acetaminophen in $0.1 \mathrm{~mol} \mathrm{~L}^{-1}$ phosphate 


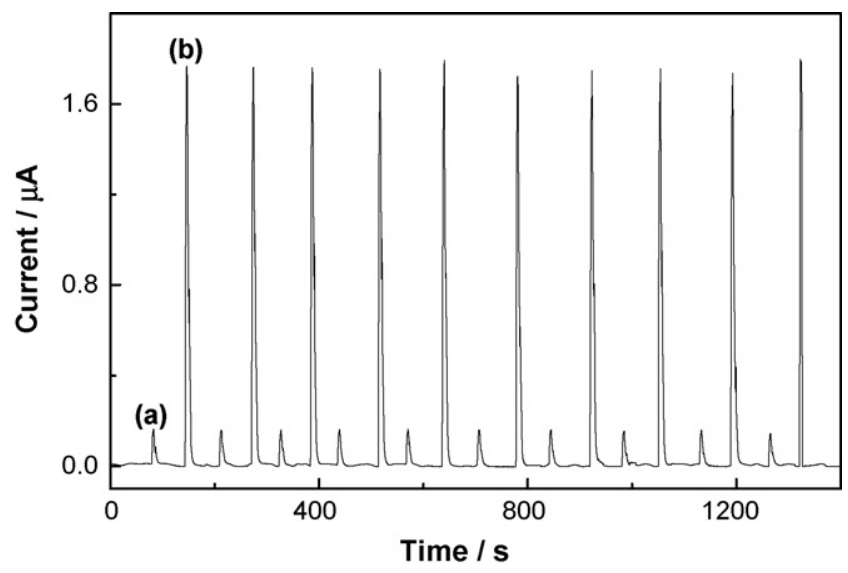

Fig. 7. FIA results for alternate injections of (a) $5.0 \times 10^{-6}$, (b) $5.0 \times 10^{-5} \mathrm{~mol} \mathrm{~L}^{-1}$ acetaminophen in $0.1 \mathrm{~mol} \mathrm{~L}^{-1}$ phosphate buffer electrolyte, $\mathrm{pH}$ 8. Applied potential $+0.6 \mathrm{~V}$ vs. $\mathrm{Ag} / \mathrm{AgCl}$, flow rate $2.0 \mathrm{~mL} \mathrm{~min}^{-1}$, sample loop $150 \mu \mathrm{L}$.

buffer electrolyte. Each possible contaminant was first added to have the same concentration as that of acetaminophen and then another addition was made so that the concentration of interferent was 10 times that of acetaminophen. Caffeine, lactose, citric acid, glucose and ascorbic acid, all of which can be present in the acetaminophen samples, were tested. Caffeine, lactose, citric acid and glucose were found to cause less than a $5 \%$ increase of the height of acetaminophen current peak, even when present in a 10-fold excess. The presence of ascorbic acid at a concentration equal to that of acetaminophen was sufficient to cause a $10 \%$ increase of the acetaminophen signal. Even so, for samples which contain ascorbic acid, this analyte can be decomposed enzymatically with ascorbate oxidase and a dif-

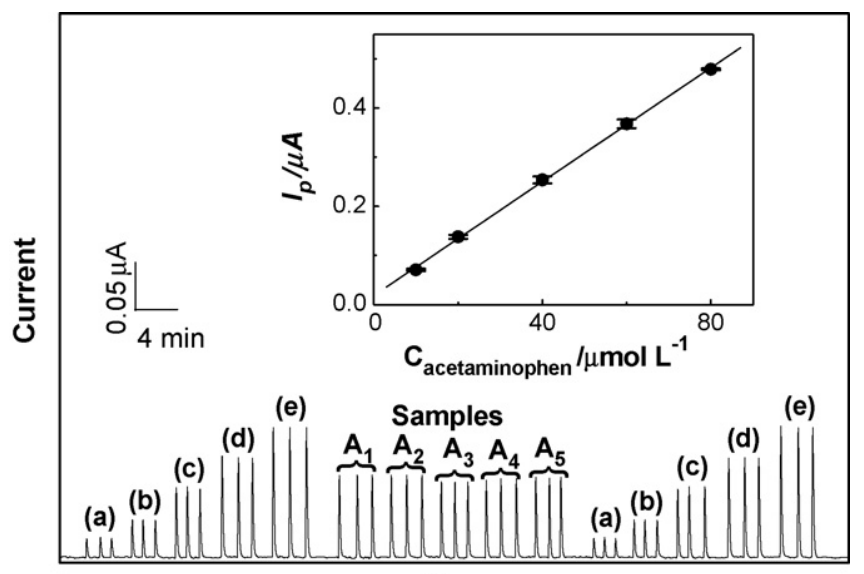

Time

Fig. 8. Analysis of the acetaminophen samples $\mathrm{A}_{1}-\mathrm{A}_{5}$ using carbon film electrode in $0.1 \mathrm{~mol} \mathrm{~L}^{-1}$ phosphate buffer electrolyte, $\mathrm{pH}$ 8. Inset: calibration plot obtained before and after injections of (a) 1.0, (b) 2.0, (c) 4.0, (d) 6.0, (e) $8.0 \times 10^{-5} \mathrm{~mol} \mathrm{~L}^{-1}$ acetaminophen standard solutions. Applied potential $+0.6 \mathrm{~V}$ vs. $\mathrm{Ag} / \mathrm{AgCl}$, flow rate $2.0 \mathrm{~mL} \mathrm{~min}^{-1}$, sample loop $150 \mu \mathrm{L}$.

ferential determination of the two compounds can be achieved $[45,46]$.

\subsubsection{Acetaminophen determination in real samples}

For analyses of real samples, five different commercial pharmaceutical tablet formulations containing acetaminophen were employed. Fig. 8 illustrates results of FIA signals obtained for these samples, preceded and followed by a series of injections of standard solutions of acetaminophen (from 1.0 until $8.0 \times 10^{-5} \mathrm{~mol} \mathrm{~L}^{-1}$ ). The proportionality between the amperometric signal and the concentration of acetaminophen standard

Table 1

Results obtained after analyses of acetaminophen in five commercial pharmaceutical samples by FIA and UV spectrophotometry (254 nm) [8].

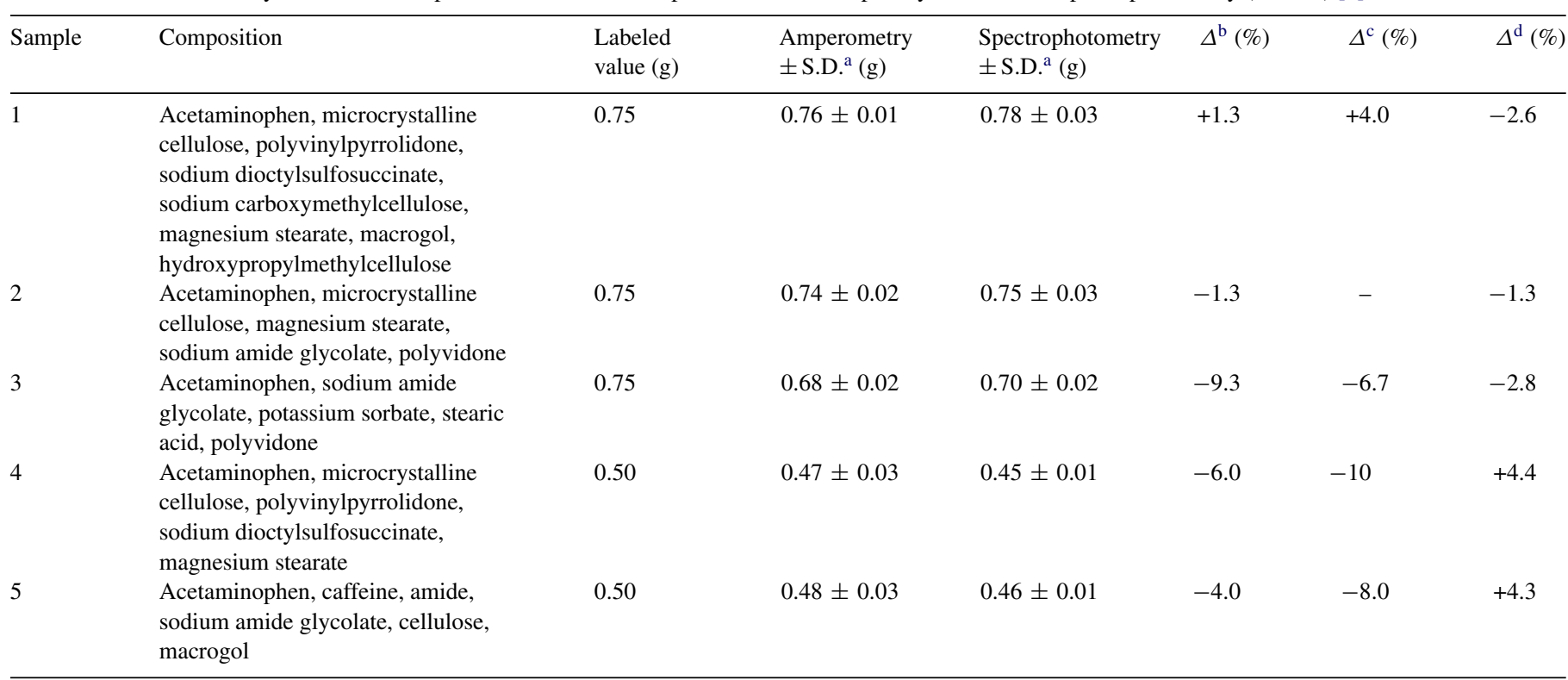

\footnotetext{
${ }^{a}$ Average \pm standard deviation for three determinations.

${ }^{\mathrm{b}}$ Relative difference between: labeled value and proposed amperometric method.

${ }^{c}$ Relative difference between labeled value and spectrophotometric method.

d Difference between the results obtained using amperometric and spectrophotometric method.
} 
solution was confirmed from the calibration plot shown in the inset. The amperometric results obtained with the new sensor were compared with those from the spectrophotometric method, recommended in the Brazilian Pharmacopoeia [8].

The results of the analyses of all samples are summarized in Table 1, where the data obtained for each commercial drug are presented. The composition of each pharmaceutical tablet is also included in order to show the components present in each unit as well as the amount of acetaminophen expected in each tablet. It can be seen from the results obtained utilizing the amperometric and spectrophotometric methods, as well as from the respective standard deviations, that the relative differences between the results obtained by the two methods and the labeled values are small. Therefore, the carbon film electrode used in a FIA provides values in good agreement with the concentration of acetaminophen specified by the pharmaceutical company, as well as those found by the recommended spectrophotometric method [8].

\section{Conclusion}

The results obtained in this work demonstrated the potentiality for carbon film resistor electrodes combined with FIA-amperometric detection for acetaminophen determination in pharmaceutical formulations. The high sensitivity provided by amperometry associated with the low cost of the sensor, makes this method very suitable for quality control applications. Moreover, carbon film electrodes provide good selectivity and excellent sensitivity for acetaminophen quantification in relatively complex commercial drugs without any surface modification. Finally, the method proposed has a low, submicromolar detection limit with excellent reproducibility and without any sample pre-treatment, such as separation, filtration, extraction or derivatization.

\section{Acknowledgements}

The authors gratefully acknowledge the financial support from Brazilian Foundations (FAPESP, CNPq, CAPES) and Fundação para a Ciência e Tecnologia (FCT) Portugal, ICEMS (Research Unit 103). This work was also partially supported with grants of $\mathrm{IM}^{2} \mathrm{C}$ project, RENAMI and SAMUTI projects.

\section{References}

[1] A. Wade (Ed.), Martindale, The Extra Pharmacopoeia, 27th ed., The Pharmaceutical Press, London, 1979, pp. 32-34.

[2] F.L. Martin, A.E. McLean, Drug Chem. Toxicol. 21 (1998) 477494.

[3] C.A. Mugford, J.B. Tarloff, Toxicol. Lett. 93 (1997) 15-22.

[4] H.T. Nagasawa, D.W. Shoeman, J.F. Cohen, W.B. Rathbun, J. Biochem. Toxicol. 11 (1996) 289-295.

[5] P.T. Kissinger, D.A. Roston, J.J. Van Benschoten, J.Y. Lewis, W.R. Heineman, J. Chem. Educ. 60 (1983) 772-776.
[6] D.J. Miner, J.R. Rice, R.M. Riggin, P.T. Kissinger, Anal. Chem. 53 (1981) 2258-2263.

[7] The United States Pharmacopoeia-The National Formulary-USP 23; NF18, Twinbrook Parkway, Rockville, 1995, pp. 16-21.

[8] Farmacopéia Brasileira, 3rd ed., Organização Andrei Ed. S.A., São Paulo, 1977, pp. 656-659.

[9] J. Hanaee, Pharm. Acta Helv. 72 (1997) 239-241.

[10] F.A. Mohamed, M.A. Abdallah, S.M. Shammat, Talanta 44 (1997) 61-68.

[11] Z. Bouhsain, S. Garrigues, M. de la Guardia, Fresenius J. Anal. Chem. 357 (1997) 973-976.

[12] S. Zhao, W. Bai, H. Yuan, D. Xiao, Anal. Chim. Acta 559 (2006) 195-199.

[13] D. Easwaramoorthy, Y.C. Yu, H.J. Huang, Anal. Chim. Acta 439 (2001) 95-100.

[14] S. Ravisankar, M. Vasudevan, M. Gandhimathi, B. Suresh, Talanta 46 (1998) 1577-1581.

[15] F.Y. He, A.L. Liu, X.H. Xia, Anal. Bioanal. Chem. 379 (2004) 1062-1067.

[16] A. Kunkel, S. Gunter, H. Watzig, J. Chromatogr. A 768 (1997) 125-133.

[17] O. Fatibello-Filho, K.O. Lupetti, I.C. Vieira, Talanta 55 (2001) 685-692.

[18] P.A. Vaughan, L.D.L. Scott, J.F. Mcaleer, Anal. Chim. Acta 248 (1991) 361-365.

[19] I.C. Vieira, K.O. Lupetti, O. Fatibello-Filho, Quím. Nova 26 (2003) 39-43.

[20] M.S.M. Quintino, K. Araki, H.E. Toma, L. Angnes, Electroanalysis 14 (2002) 1629-1634.

[21] M. Knochen, J. Giglio, B.F. Reis, J. Pharm. Biomed. Anal. 33 (2003) 191-197.

[22] M.K. Srivastava, S. Ahmed, D. Singh, I.C. Shukla, Analyst 110 (1985) 735-737.

[23] M.L. Ramos, J.F. Tyson, D.J. Curran, Anal. Chim. Acta 364 (1998) 107-116.

[24] Z. Bouhsain, S. Garrigues, A. Morales-Rubio, M. de la Guardia, Anal. Chim. Acta 330 (1996) 59-69.

[25] M.L. Ramos, J.F. Tyson, D.J. Curran, Anal. Chim. Acta 364 (1998) $107-116$.

[26] K.K. Verma, A. Jain, K.K. Stewart, Anal. Chim. Acta 261 (1992) 261-267.

[27] A.F. Lavorante, C.K. Pires, B.F. Reis, J. Pharm. Biomed. Anal. 42 (2006) 423-429.

[28] J.F. van Staden, M. Tsanwani, Talanta 58 (2002) 1095-1101.

[29] R.N. Goyal, V.K. Gupta, M. Oyama, N. Bachheti, Electrochem. Commun. 7 (2005) 803-807.

[30] V.A. Pedrosa, D. Lowinsohn, M. Bertotti, Electroanalysis 18 (2006) 931-934.

[31] Y. Fang, D. Long, J. Ye, Anal. Chim. Acta 342 (1997) 13-21.

[32] N.F. Atta, A. Galal, E. Karagötzer, G.C. Russell, H. Zimmer, H.B. Mark Jr., Biosens. Bioelectron. 6 (1991) 333-341.

[33] M. Boopathi, M. Won, Y. Shim, Anal. Chim. Acta 512 (2004) 191-197.

[34] N. Wangfuengkanagul, O. Chailapakul, J. Pharm. Biomed. Anal. 28 (2002) 841-847.

[35] C.M.A. Brett, L. Angnes, H.D. Liess, Electroanalysis 13 (2001) 765-769.

[36] O.M.S. Filipe, C.M.A. Brett, Electroanalysis 16 (2004) 994-1001.

[37] O.M.S. Filipe, C.M.A. Brett, Talanta 61 (2003) 643-650.

[38] C. Gouveia-Caridade, R. Pauliukaite, C.M.A. Brett, Electroanalysis 18 (2006) 854-861.

[39] M. Florescu, C.M.A. Brett, Talanta 65 (2005) 306-312.

[40] M.E. Ghica, C.M.A. Brett, Anal. Chim. Acta 532 (2005) 145-151.

[41] R. Pauliukaite, M.E. Ghica, C.M.A. Brett, Anal. Bioanal. Chem. 381 (2005) 972-978.

[42] M.E. Ghica, C.M.A. Brett, Electroanalysis 18 (2006) 748-756.

[43] M.A.T. Gilmartin, J.P. Hart, Analyst 119 (1994) 2431-2437.

[44] C.M.A. Brett, A.M. Oliveira Brett, Electrochemitsry. Principles, Methods and Applications, Oxford University Press, Oxford, 1993, pp. 197-201.

[45] J. Wang, N. Naser, M. Ozsoz, Anal. Chim. Acta 234 (1990) 315-320.

[46] R.C. Matos, M.A. Augelli, J.J. Pedrotti, C.L. Lago, L. Angnes, Electroanalysis 10 (1998) 887-890. 